left HJ (Table 1). There were no statistical differences between MRI symptoms of the impairment HJ and US symptoms of coxitis at baseline and after 2 years (Table 2).

Radiographic progression (BASRI-hip $\geq 1$ stage) after 2 years follow-up founded in $7(31,8 \%)$ pts with MRI symptoms of the impairment HJ. There are radiographic progression from normal $\mathrm{HJ}$ to bilateral stage 1 in $5(71,4 \%)$ pts, from bilateral stage 1 to bilateral stage 2 in $2(28,6 \%)$ pts. Mean NSAID index in pts with radiographic progression $(31,8 \%)$ amount $62,2 \%$, while in pts without radiographic progression $-72,5 \%(p=0,2)$.

Conclusions: 1. In patients with early axial spondyloarthritis in two years of observation radiographic progression observed in $31,7 \%$ patients despite on regular intake of NSAIDs. 2. Further studies of the impairment $\mathrm{HJ}$ are required in patients with axial SpA.

Disclosure of Interest: None declared

DOI: 10.1136/annrheumdis-2017-eular.3985

\section{SAT0395 SIMILARITIES AND DIFFERENCES BETWEEN NON-RADIOGRAPHIC AND RADIOGRAPHIC AXIAL SPONDYLOARTHRITIS IN PROOF COHORT}

D. Poddubnyy ${ }^{1}$, R.D. Inman ${ }^{2}$, J. Sieper ${ }^{1}$, S. Akar ${ }^{3}$, S. Muñoz-Fernández ${ }^{4}$, M. Hojnik ${ }^{5} \cdot{ }^{1}$ Charité Universitätsmedizin Berlin, Berlin, Germany: ${ }^{2}$ Toronto Western Hospital, Toronto, Canada; ${ }^{3}$ Izmir Katip Celebi University School of Medicine, Izmir, Turkey; ${ }^{4}$ Hospital Universitario Infanta Sofía, Universidad Europea, Madrid, Spain; ${ }^{5}$ AbbVie, Ljubljana, Slovenia

Background: Previously, some differences between non-radiographic and radiographic axial spondyloarthritis (axSpA) - such as a higher prevalence of females and lower level of acute phase reactants in non-radiographic axSpA (nr-axSpA) have been reported in national observational studies, mostly from Europe.

Objectives: To compare demographic and clinical characteristics of patients (pts) with $\mathrm{nr}-\mathrm{axSpA}$ and radiographic axSpA (ankylosing spondylitis, AS) in a large multinational cohort of pts with recently diagnosed axSpA.

Methods: PROOF is a prospective observational study evaluating clinical and radiographic outcomes in axSpA pts in rheumatology clinical practice in 29 countries. Pts with axSpA fulfilling ASAS classification criteria were eligible if diagnosed $\leq 1$ year prior to study enrolment. Investigator's confidence with the diagnosis of axSpA was ascertained on a numeric rating scale (NRS 0-10) at enrolment and end of follow-up. At baseline, demographic and clinical data related to the diagnosis, disease activity, quality of life and work productivity, as well as conventional radiographs of the sacroiliac joints were collected. Classification as nr-axSpA or AS was based on the results of the assessment of sacroiliac radiographs. Available radiographs were assessed first by a local reader and then by a central reader according to the grading system of the modified New York criteria. In the case of a disagreement in the classification (nr- axSpA or $\mathrm{AS}$ ), the radiograph was evaluated by the 2 nd central reader, who was blinded to the previous assessments and the final classification was made based on the decision of 2 out of 3 readers.

Results: Of the 2126 pts enrolled in PROOF, 1281 (60.3\%) pts were classified as AS and $845(39.7 \%)$ as $\mathrm{nr}$-axSpA according to investigators. The confidence with the diagnosis of axSpA was $8.7 \pm 1.8$. The final classification according to the central assessment of sacroiliac radiographs was confirmed in1583 pts included in this analysis. A total of 987 pts (62.3\%) were classified as AS and 596 (37.7\%) as $n r-a x S p A$. AS pts expectedly had longer symptom duration, more frequently had elevated and higher CRP and were more often male and treated with TNF inhibitors (Table). In addition, HLA-B27 positivity was more frequent among AS pts, while pts with nr-axSpA had a significantly higher prevalence of enthesitis, psoriasis, and inflammatory bowel disease (IBD). The prevalence of other SpA features was comparable between the two subgroups of axSpA. Mostly, ptreported outcomes reflecting burden of disease were comparable between the two subgroups, but BASDAI was significantly higher in the nr-axSpA subgroup (Table). Conclusions: There were a few differences between nr-axSpA and AS pts in the PROOF cohort. The clinical constellation of female sex, low CRP, enthesitis, psoriasis, and IBD in nr-axSpA pts appears to reflect a phenotype less prone to structural damage in the sacroiliac joints. However, the clinical burden of disease was comparable between the two subgroups of axSpA.

Acknowledgements: AbbVie funded the PROOF study, contributed to its design and participated in data collection, analysis and interpretation of the data, and in writing, review, and approval of the publication. Medical writing support was provided by Deepa Venkitaramani, PhD, of AbbVie.

Disclosure of Interest: D. Poddubnyy Grant/research support from: AbbVie, Janssen, MSD, Novartis, Pfizer, Consultant for: AbbVie, BMS, Boehringer, MSD, Novartis, Pfizer, and UCB, Speakers bureau: AbbVie, BMS, Janssen, MSD, Novartis, Pfizer, Roche, and UCB, R. Inman Grant/research support from: AbbVie, Amgen, and Janssen, Consultant for: AbbVie, Amgen, Janssen, Lilly, Novartis, and Pfizer, J. Sieper Grant/research support from: AbbVie, Merck, and Pfizer, Consultant for: AbbVie, Janssen, Lilly, Merck, Novartis, Pfizer, and UCB, Speakers bureau: AbbVie, Janssen, Merck, Novartis, Pfizer, Roche, and UCB, S. Akar Grant/research support from: AbbVie, BMS, MSD, Novartis, Pfizer, Roche, and UCB, Consultant for: AbbVie, BMS, MSD, Novartis, Pfizer, Roche, and UCB, Speakers bureau: AbbVie, BMS, MSD, Novartis, Pfizer, Roche, and UCB, S. Muñoz-Fernández Grant/research support from: Abbvie, BMS, Janssen, MSD, Novartis, Pfizer, Roche, and UCB, Consultant for: Abbvie, BMS, Janssen, MSD,
Table Baseline demographic and clinical characteristics of patients from PROOF cohort.

\begin{tabular}{|c|c|c|c|c|}
\hline \multicolumn{2}{|l|}{ Characteristic } & $\begin{array}{l}\text { nr-axSpA } \\
(\mathrm{N}=544)\end{array}$ & $\begin{array}{c}A S \\
(N=1039)\end{array}$ & P-value ${ }^{a}$ \\
\hline \multicolumn{2}{|c|}{ Age, years, mean \pm SD } & $35.5 \pm 9.8$ & $34.5 \pm 11.1$ & .070 \\
\hline \multicolumn{2}{|c|}{ Duration since back pain onset, months, mean $\pm S D$} & $48.7 \pm 69.2$ & $62.4 \pm 90.9$ & .001 \\
\hline \multicolumn{2}{|c|}{ Duration since diagnosis, months, mean \pm SD } & $2.8 \pm 5.6$ & $4.0 \pm 20.2$ & 119 \\
\hline \multicolumn{2}{|l|}{ Male sex, $n(\%)$} & $264(48.5)$ & $737(71.0)$ & $<.001$ \\
\hline \multirow{11}{*}{ SpA parameters } & HLA-B27 (+), n (\%) & $254(55.3)^{b}$ & $591(69.0)^{c}$ & $<.001$ \\
\hline & Inflammatory back pain, $\mathbf{n}(\%)$ & $512(94.1)$ & $991(95.4)$ & 279 \\
\hline & Peripheral arthritis, $\mathbf{n}(\%)$ & $171(31.4)$ & $343(33.0)$ & 535 \\
\hline & Enthesitis (heel), $n(\%)$ & $214(39.3)$ & $348(33.5)$ & .023 \\
\hline & Dactylitis, $n(\%)$ & $32(5.9)$ & $57(5.5)$ & .732 \\
\hline & Uveitis, $\mathbf{n}(\%)$ & $49(9.0)$ & $106(10.2)$ & 477 \\
\hline & Psoriasis, $\mathbf{n}(\%)$ & $54(9.9)$ & $59(5.7)$ & .003 \\
\hline & IBD, $n(\%)$ & $23(4.2)$ & $18(1.7)$ & .004 \\
\hline & Good response to NSAIDs, $n(\%)$ & $324(59.6)$ & $636(61.2)$ & .551 \\
\hline & Family history of SpA, $n(\%)$ & $101(18.6)$ & $196(18.9)$ & 946 \\
\hline & Elevated CRP, $\mathbf{n}(\%)$ & $178(32.7)$ & $555(53.4)$ & $<.001$ \\
\hline \multicolumn{2}{|c|}{ Number of positive SPA parameters, mean \pm SD } & $3.5 \pm 1.4$ & $3.8 \pm 1.4$ & .001 \\
\hline \multicolumn{2}{|l|}{ CRP, $m g / l$, mean $\pm S D$} & $11.5 \pm 19.5$ & $17.6 \pm 24.3$ & $<.001$ \\
\hline \multicolumn{2}{|c|}{ ASDAS-CRP, mean \pm SD } & $2.8 \pm 1.1$ & $3.0 \pm 1.1$ & .004 \\
\hline \multicolumn{2}{|c|}{ BASDAI, points NRS $(0-10)$, mean $\pm S D$} & $4.8 \pm 2.4$ & $4.3 \pm 2.3$ & $<.001$ \\
\hline \multicolumn{2}{|c|}{ Patient global, points NRS $(0-10)$, mean \pm SD } & $5.0 \pm 4.8$ & $4.8 \pm 4.6$ & 188 \\
\hline \multicolumn{2}{|c|}{ BASFI, points NRS $(0-10)$, mean $\pm S D$} & $3.4 \pm 2.5$ & $3.3 \pm 2.5$ & 815 \\
\hline \multicolumn{2}{|c|}{ SF-12V2, physical component score, mean \pm SD } & $40.9 \pm 8.9$ & $41.0 \pm 8.8$ & 698 \\
\hline \multicolumn{2}{|c|}{ SF-12V2, mental component score, mean \pm SD } & $42.9 \pm 10.9$ & $43.7 \pm 10.4$ & .166 \\
\hline \multicolumn{2}{|c|}{ WPAI-SHP - total activity impaiment, mean \pm SD } & $44.9 \pm 28.1$ & $43.1 \pm 27.4$ & 208 \\
\hline \multirow{6}{*}{ Current Treatment } & NSAIDs, $n(\%)$ & $428(78.7)$ & $800(77.0)$ & 485 \\
\hline & Methotrexate, $n(\%)$ & $40(74)$ & $63(6.1)$ & 335 \\
\hline & Sulfasalazine, $n,(\%)$ & $117(21.5)$ & $253(24.4)$ & 212 \\
\hline & Steroids, $\mathbf{n}(\%)$ & $40(7.4)$ & $85(8.2)$ & 624 \\
\hline & Analgesics, $\mathbf{n}(\%)$ & $98(18.0)$ & $144(13.9)$ & .033 \\
\hline & TNF $\alpha$ inhibitors, $n(\%)$ & $48(8.8)$ & $165(15.9)$ & $<.001$ \\
\hline
\end{tabular}

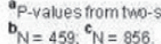

$\mathrm{nr}-\mathrm{ax} \mathrm{SPA}=$ = non-radiographic axial spondyloarthritis; $\mathrm{AS}=$ Ankylosing spondylitis; $\mathrm{SD}=$ standard deviation; $\mathrm{SpA}=$ spondyloarthrtis, $\mathrm{HLA} \cdot \mathrm{B} 27=$ human leukocyte antigen $\mathrm{B} 27 ; \mathrm{IBD}=$ inflammatory bowel disease; NSAIDs = nonsteroidal antl-inflammatory drugs; $C R P=C$-reactive protein; $A$ SDAS-CRP $=$ Ankylosing Spondylitis Disease Activit Score containing CRP; BASDAI = Bath Arkylosing Spondylitis Disease Activty Index; NRS = numeric rating scale; BASFI = Bath Ankylosing Spondylitis Functional Index, SF-12v2=Short form 12-item health survey, WPAI-SHP = Work productivity impaiment Questionnaire-specfic heath problem, TNF = fumor necrosis factor

Novartis, Pfizer, Roche, and UCB, Speakers bureau: Abbvie, BMS, Janssen, MSD, Novartis, Pfizer, Roche, and UCB, M. Hojnik Shareholder of: AbbVie, Employee of: AbbVie

DOI: 10.1136/annrheumdis-2017-eular.2001

\section{SAT0396 INVESTIGATION OF IRON DEFICIENCY ANEMIA IN ANKYLOSING SPONDYLITIS PATIENTS}

Y. Bulut ${ }^{1,2,3}$, D. Arslan Tas ${ }^{4}$, O. Goruroglu Ozturk ${ }^{2}$, U. Karaogullarindan ${ }^{3}$. ${ }^{1}$ Cukurova University, Faculty of Medicine, ADANA, Turkey; ${ }^{2}$ Biochemistry;

${ }^{3}$ Internal Medicine; ${ }^{4}$ Rheumatology-Immunology Department, Cukurova University, Faculty of Medicine, ADANA, Turkey

Background: It is reported that subclinic intestinal inflammation may occur in Ankylosing spondylitis (AS) patients, besides, using NSAIDs cause peptic and duedenal ulcers. \%50-60 of AS patients have asymptomatic ileal and colonic mucosal inflammation. It is reported that inflammatory bowel disease (IBD) is found in $5-10 \%$ of AS patients and $4-10 \%$ of IBD patients have concomittant findings with AS. These conditions may cause iron deficiency anemia (IDA).

Objectives: It is well known that chronic disease anemia is a frequent finding in AS patients. But there is no study in the literature about relationship between AS patients and IDA. In this particular study we aimed to asses frequency of IDA in AS patients and to investigate the etiologies of IDA.

Methods: Ninety four consecutive AS patients who meet 2012 ASAS/EULAR criteria, who were followed Çukurova University Romatology Clinic, were icluded. We investigated the etiologies of IDA in anemic patients. Twenty six AS patients were diagnosed as IDA. Twenty six patients without anemia were assigned as a control group. Hepcidin, soluble transferrin receptor1 (sTfR1) and anemia parameters were tested in both groups. Findings were anayzed with SPSS version 23.

Results: Twenty six of 94 AS patients were diagnosed as IDA (\%27). Frequency of IDA in our AS patients was higher when compared to the IDA prevalence in the society (\%1-2). Endoscopy and colonoscopy were performed for searching etiology of IDA. Mucosal inflammation was found in $62 \%$ of patients by endoscopy and $11 \%$ of patients by colonoscopy. One patient was diagnosed as Crohn's disease and one patient was diagnosed as Coeliac disease histopathologically. Hepcidin was found to be significantly lower in IDA patients $(p<0.01)$. We found sTfR1 levels significantly higher in IDA patients $(p<0,01)$. BASDAI (Bath Ankylosing Spondylitis Disease Activity Index) and sedimentation values were found to be higher in IDA patients statistically ( $p<0.01$ and $p=0.01$ respectively). Although we found $\mathrm{C}$ - reactive protein (CRP) values were higher when compared to the non- anemic patients; however it was not statistically significant $(p>0.05)$. Conclusions: We found higher frequency of IDA when compared to the normal 
population. We found that AS was more active in patients who were diagnosed as IDA. We suggest that AS activitiy may cause mucosal inflammation and subsequently may result as IDA. Also we found that mucosal inflammation in AS patients is not related to NSAIDs because there was no difference about mucosal lesions between NSAID taking and non-NSAID taking group. No study was met in the literature concerning AS and IDA. Our findings should be supported by further studies.

\section{References:}

[1] Rudwaleit M, Baeten D. Ankylosing spondylitis and bowel disease. Best Pract Res Clin Rheumatol 2006; 20(3):451-71.

[2] Lanas A, Boers M, Nuevo J. Gastrointestinal events in at-risk patients starting non-steroidal anti-inflammatory drugs (NSAIDs) for rheumatic diseases: the EVIDENCE study of European routine practice. Ann Rheum Dis. 2015;74(4):675-81.

[3] Niccoli L, Nannini C, Cassarà E, Kaloudi O, Cantini F. Frequency of anemia of inflammation in patients with ankylosing spondylitis requiring anti-TNF $\alpha$ drugs and therapy-induced changes. Int J Rheum Dis. 2012;15(1):56-61.

Disclosure of Interest: None declared

DOI: 10.1136/annrheumdis-2017-eular.5913

\section{SAT0397 RISK FACTORS FOR DEVELOPMENT AND PERSISTENCE OF CHRONIC WIDESPREAD PAIN, IN ANKYLOSING SPONDYLITIS AND UNDIFFERENTIATED SPONDYLOARTHRITIS}

E. Mogard ${ }^{1}$, E. Lindqvist ${ }^{1}$, A. Bremander ${ }^{2,3}$, S. Bergman $2,4 .{ }^{1}$ Department of Clinical Sciences, Section of Rheumatology and Skåne University Hospital; ${ }^{2}$ Department of Clinical Sciences, Section of Rheumatology, Lund University, Lund; ${ }^{3}$ School of Business, Engineering and Science, Halmstad University, Halmstad; ${ }^{4}$ Primary Health Care Unit, Department of Public Health and Community Medicine, Institute of Medicine, Sahlgrenska Academy, University of Gothenburg, Gothenburg, Sweden

Background: Chronic back pain is a prominent symptom in Spondyloarthritis $(\mathrm{SpA})$, and an important contributor to diminished quality of life $(1,2)$. Chronic pain can develop in intensity, become more spread, and progress to chronic widespread pain (2). Mechanisms for this are yet inconsistent (3), and in SpA, knowledge of progression to chronic widespread pain (CWP) is lacking.

Objectives: To study the development of CWP in patients with SpA, and to identify risk factors for development and persistence of CWP.

Methods: A cohort study with baseline and 2.5-year follow-up postal surveys. 644 patients (47\% women) with ankylosing spondylitis (AS) and undifferentiated spondyloarthritis $(\mathrm{SpA})$ answered both surveys, and were categorized as no chronic pain (NCP), chronic regional pain (CRP), and CWP. Logistic regression analyses, with CWP as the main outcome were performed. Due to multicollinearity, each risk factor candidate (disease duration, BMI, smoking, and different patient-reported outcome measures; PROMs) were analysed in separate logistic regression models together with a base model (age, sex, and SpA-subgroup).

Results: At follow-up, prevalence estimates for NCP, CRP and CWP were similar to those at baseline, but $38 \%$ of the patients had transitioned between the groups. A large group, $72 \%$ of the patients with initial CWP, also reported persistent CWP at follow-up (Figure). Risk factors (OR and $95 \% \mathrm{Cl}$ ) for development of CWP from initial NCP/CRP were more pain regions $(1.36 ; 1.20-1.53)$, pain intensity $(1.35$; $1.20-1.52)$, fatigue (1.25; 1.13-1.38), global health $(1.35 ; 1.19-1.54)$, EQ-5D $(0.05 ; 0.01-0.19)$, BASDAI $(1.25 ; 1.07-1.45)$, BASFI $(1.32 ; 1.16-1.50)$, ASES pain $(0.97 ; 0.96-0.99)$, ASES symtom $(0.98 ; 0.97-0.99)$, and HADb $(1.10 ; 1.02$ - 1.19). The risk factors for persistent CWP, compared to patients transitioning to NCP or CRP, were similar to those predicting development of CWP, but in addition, also higher age $(1.02 ; 1.00-1.04)$, and female sex $(1.82 ; 1.06-3.10)$, predicted the outcome.

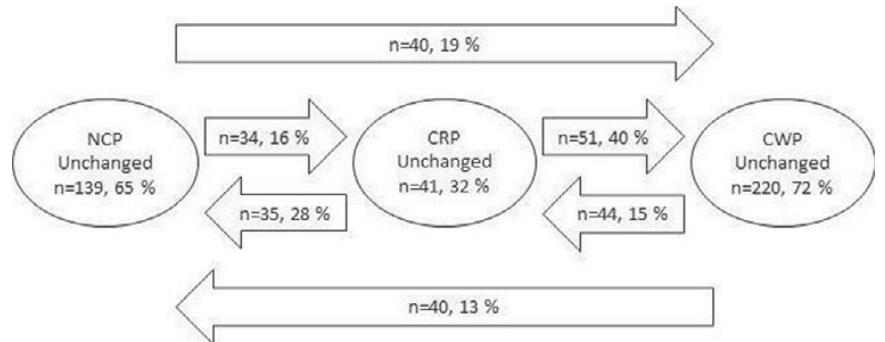

Figur 1. Transition of patients to and from the pain groups (NCP, CRP, CWP) between 2009 and 2011. Pearson Chi-Squaretest $p \leq 0.001$.

Conclusions: The total prevalence of CWP did not change over the study-period, although a substantial transition between the pain-groups were found. More pain regions, higher pain intensity, fatigue and worse self-reported health predicted the development into CWP, and persistent CWP. Also, higher age and female sex were risk factors for persistent CWP in SpA. Special attention in patients who report increased pain and related symtoms is essential, to early identify the development of CWP in patients with SpA.

References:

[1] Dougados M et al. The European Spondyloarthropathy Study Group pre- liminary criteria for the classification of spondyloarthropathy. Arthritis Rheum $1991 ; 34: 1218-27$

[2] Kiltz $U$ et al. Do patients with non-radiographic axial spondyloarthrits differ from patients with ankylosing spondylitis? Arthritis Care Res (Hoboken) 2012;64:1415-22.

[3] Bergman $S$ et al. Chronic widespread pain: a three year followup of pain distribution and risk factors J Rheumatol 2002;29:818-825.

[4] Larsson B et al. A systematic review of risk factors associated with transitioning from regional musculoskeletal pain to chronic widespread pain. Eur J Pain 2012:16:1084-1093.

Disclosure of Interest: None declared

DOI: 10.1136/annrheumdis-2017-eular.3445

\section{SAT0398 PREGNANCY OUTCOMES IN KOREAN WOMEN WITH ANKYLOSING SPONDYLITIS}

E.H. Park ${ }^{1}$, J.K. Jun ${ }^{2}$, S.M. Lee ${ }^{2}$, Y.W. Song ${ }^{1}$, E.B. Lee ${ }^{1} .{ }^{1}$ Division of Rheumatology, Department of Internal Medicine; ${ }^{2}$ Department of Obstetrics and Gynecology, Seoul National University College of Medicine, Seoul, Korea, Republic Of

Background: Ankylosing spondylitis (AS) is a chronic, systemic, inflammatory disease that primarily affects the sacroiliac joints and spine. Despite overwhelming prevalence of AS in men, it can also occur in women. Since AS mainly affects the sacroiliac joints, a special attention should be paid to the normal labors and pregnancy outcomes in these female patients. However, very little is known about the impact of AS on pregnancy outcomes due to rare occurrence of the disease in women.

Objectives: To investigate the pregnancy outcomes in Korean female patients with AS.

Methods: All of the 27 deliveries from 20 AS female patients who had been cared at Seoul National University Hospital between February 1994 and June 2016 were retrospectively evaluated through medical record review. After matching each pregnancy of the AS women with the pregnancies of the control group on a 1 to 4 ratio based on maternal and gestational age, pregnancy outcomes of AS patients were compared with those of the control group. Pregnancy outcomes included cesarean section (CS) rate, preterm birth, low birth weight infant, fetal growth restriction (FGR), fetal malformations and preeclampsia. Each pregnancy was considered as a separate observation, and outcomes between the groups were compared by regression models estimated using Generalized Estimating Equations (GEEs) to account for the matched nature of the data. For zero events in either group in which GEE models do not converge, Fisher's exact test or Chi-square test were used.

Results: Caesarean section (CS) was performed in $44.4 \%$ of deliveries among women with AS compared with $20.4 \%$ in controls $(p=0.002)$ (Table 1). The indications of CS included previous uterine surgery, breech position, placenta previa, placental abruption, fetal distress, and cephalopelvic disproportion (CPD), which were comparable between two groups. When excluding the cases of elective CS, 16 pregnant women with AS were tried for the vaginal delivery. Among them, 15 cases (93.8\%) achieved successful vaginal deliveries, which was comparable to the successful vaginal delivery rate in controls (86/90 (95.6\%), $p=0.566)$. CS due to CPD was done in 1 case $(8.3 \%)$ of AS women, while there was no case in the controls $(p=0.353)$. Interestingly, the severity of sacroiliitis in AS patients did not show any association with CS $(p=0.342)$. Women with AS had a higher frequency of LBW compared to the controls $(22.2 \%$ vs $8.3 \%$, $\mathrm{p}=0.024)$. However, there was no statistically significant difference in other adverse pregnancy outcomes, including preterm birth, FGR, fetal malformations, and pre-eclampsia.

Table 1. Overall pregnancy outcomes

\begin{tabular}{lccc} 
Characteristics & $\begin{array}{c}\text { Pregnancies with } \\
\text { AS } \\
(\mathrm{n}=27)\end{array}$ & $\begin{array}{c}\text { Pregnancies } \\
\text { without AS } \\
(\mathrm{n}=108)\end{array}$ & $p$-value ${ }^{1)}$ \\
\hline Caesarian section delivery, $\mathrm{n}(\%)$ & $12(44.4)$ & $22(20.4)$ & 0.002 \\
Fetal loss, $\mathrm{n}(\%)$ & $0(0.0)$ & $0(0.0)$ & - \\
Maternal death, n (\%) & $0(0.0)$ & $0(0.0)$ & - \\
Preeclampsia, n (\%) & $0(0.0)$ & $4(3.7)$ & $0.583^{*}$ \\
Twin pregnancy, n (\%) & $5(18.5)$ & $8(7.4)$ & 0.016 \\
Fetal malformation, $\mathrm{n}(\%)$ & $1(3.7)$ & $1(0.9)$ & 0.329 \\
Transfusion, $\mathrm{n}(\%)$ & $1(3.7)$ & $2(1.9)$ & 0.577 \\
Hospital stay, days, mean (SD) & $4.1(2.9)$ & $5.1(7.9)$ & 0.283 \\
Sex of child, female, $\mathrm{n}(\%)^{* *}$ & $17(53.1)$ & $63(54.8)$ & 0.883 \\
Neonatal weight, g, mean (SD) & $2960.3(523.8)$ & $3065.3(509.4)$ & 0.370 \\
1 min Apgar Score $<4, \mathrm{n}(\%) * *$ & $1(3.1)$ & $7(6.1)$ & $>0.999$ \\
5 min Apgar Score $<7, \mathrm{n}(\%)^{* *}$ & $1(3.1)$ & $4(3.5)$ & $>0.999$
\end{tabular}

1) P-value: calculated from regression models estimated using GEEs to account for the matched nature of the data

" P-value: calculated from Fisher's exact test because of zero events in either group in which GEE models do not converge

** Analyzed by neonates and information of twins reflected, pregnancies with AS, $n=32$; pregnancies without AS. $n=115$

Conclusions: Although pregnant women with AS are concerned about CPD during their labors due to the involvement of the sacroiliac joints, vaginal deliveries 